\title{
What services are useful for patients with intellectual disability?
}

\begin{tabular}{|r|l|}
\hline Journal: & InnovAiT \\
\hline Manuscript ID & INNOVAIT-2019-CA-148.R1 \\
\hline Manuscript Type: & Clinical Article \\
\hline Manuscript Keywords: & Learning Disabilities, Ethics and Values Based Medicine \\
\hline \multicolumn{2}{|l}{} \\
\hline
\end{tabular}

\section{SCHOLARONE ${ }^{\text {M }}$ Manuscripts}




\section{What services are useful for patients with intellectual disability?}

It is well-known that people with intellectual disabilities often face a host of health inequalities and co-morbidities. These include childhood obesity, mental health problems, and challenging behaviour. People with intellectual disabilities also have reduced life expectancy. GPs are uniquely placed to advocate for and signpost these patients, ensuring they have access to appropriate support. Yet it is often unclear what resources are, in reality, both available and beneficial. Here we aim to summarise some of the common inequalities and complexities when working with patients with ID and provide an overview of some potentially helpful services.

\section{The RCGP curriculum and services for people with intellectual disability}

The role of the GP in the neurodevelopmental disorders, intellectual and social disability clinical topic guide is to:

- Identify, monitor and review all patients who have difficulties with communication, social relationships and managing their own affairs; this may require additional skills in diagnosis, examination and consultation, and an understanding of legislation and guidance on mental capacity

- Carry out annual health checks for people with intellectual disability

- Signpost patients and their families or carers to appropriate resources, knowing when and where to seek specialist help

- Advocate for people with intellectual and social disabilities; promote fairness and equity in the community, including equal access to health care.

The RCGP curriculum outlines knowledge and skills topics that may be relevant for GPs working with patients with intellectual disabilities. This paper will address the topics listed below:

- Diagnostic features and genetic causes of intellectual disability

- Common associated physical health disorders and mental health problems

- Annual health checks

- Secondary care and specialist services

\section{Terminology}

Since the inception of psychiatric nosology, various terms have been used to describe conditions affecting cognitive and adaptive functioning. Some of these are now considered at best outdated and at worst stigmatising. Throughout this article, we will use the initialism (ID) to refer to "intellectual disabilities", reflecting the language used in RCGP curriculum. In the UK and elsewhere many specialist services and indeed patients and families use the term "learning disability". Despite sounding similar, there is a firm distinction between "learning disabilities" and "learning difficulties", the latter being an umbrella term used to describe the broad spectrum of conditions which impact a specific area of learning such as literacy (dyslexia) rather than cognitive development or "intellect" and adaptive functioning as a whole. 
Understanding this distinction may be challenging for patients, families, and professionals alike. Therefore, it is important that GPs have a strong grasp of each group when making referral decisions.

\section{Definition, aetiology and prevalence of ID}

Intellectual disability (ID) is a neurodevelopmental condition which begins in the developmental period and is characterised by atypical cognitive development and differences in conceptual, social or practical adaptive functioning which are two or more standard deviations below the population mean (World Health Organisation, 2019). In the UK, the legal definition of disability comes from the Equality Act (2010), wherein differences in adaptive functioning are considered a core feature of disability. For ID specifically, the General Medical Services (GMS) contract Quality and Outcomes Framework (QOF; 2019) describe ID by three criteria: an intelligence quotient (IQ) of less than 70, impairments in social or adaptive functioning, and onset in childhood. Yet it is important to note that the range and severity of cognitive and functional differences are diverse. In an attempt to describe this diversity, psychiatric nosologies use terms such as "mild", "moderate", "severe" and "profound". Most people (approx. 85\%) with an ID fall under the categories of mild to moderate (Boat et al., 2015). Many of these patients are able to live independently though may require some additional support (e.g. when making health or legal decisions). People with severe ID, in contrast, may require greater support with tending to care needs and may need a flexible approach to communication. People in the "profound" category often require assistance with all aspects of care and might also have difficulties with symbolic communication and reasoning. However, it is essential that all decisions regarding support must be made on an individual basis rather than on the category of functioning, using appropriate approaches to allow the patient and their family to indicate preferences and make choices.

The aetiology is diverse, ranging from birth complications, prenatal substance exposure, brain injury and severe neglect, to genetic syndromes. It is estimated that in $60 \%$ of people with ID, the genetic aetiology can now be established (Vissers et al, 2017). Such genetic aetiologies include Trisomy 21 (Down's Syndrome), paternal 15q11-q13 deletion (Prader-Willi syndrome), XXY (Kinefelter syndrome) and many others. Parents and patients might also benefit from support groups such as hwww.rarechromo.org. Some syndromes associated with ID have specific patterns of cognitive and general abilities associated with them although show considerable individual variation among individuals (e.g. Mulder et al., 2017).

In England, it has been estimated that there are 1,087,100 people with ID (Public Health England, 2015). This figure stands in stark contrast with the number of people with ID on GP registers, which is approximately 252,446 (Public Health England, 2015). This equates to 4.4 people with ID per 1,000 people registered with a GP (Public Health England, 2015). Speculating on the causes for these discrepancies, Public Health England (2015) suggests that one factor may be that people tend to use GP services sporadically. Yet this is cause for concern considering that free annual health checks are recommended for everyone over the age of 14 with an ID (Public Health England, 2016). Another explanation offered by Public Health 
England (2015) is that the majority of adults with ID are not known to ID services. In support of this claim, Public Health England cites national prevalence figures that show a marked difference between the numbers of children with ID in the education system $(2.5 \%)$ and the number of people in their twenties known to services (around $0.6 \%$ ). Such a distinct drop-off, it is reasoned by the national body, might be due to increased thresholds for entry to adult specialist health and social care services, or less obvious impairments in non-educational settings. Nevertheless, there are signs that things are moving in a positive direction. That is, the numbers of people with ID on GP registers been growing at a rate of around 5\% per year. This is likely the result of non-aetiological factors such as more accurate recording-keeping. Still, it is consequential that many patients with an established ID may not have this marked in their health records or making use of potentially important or beneficial services.

\section{Health inequalities/multimorbidity}

\section{Overview}

Previous work has established that people with ID and associated conditions often face a number of health inequalities across the lifespan relative to typically developing peers. Such disparities might include greater risk of respiratory problems (e.g. Chang et al., 2017) and a reduced life expectancy (Thornton, 2019). In an analysis of 1,424,378 primary healthcare records, Cooper and collaborators (2015) identified a number of physical health comorbidities which were more prevalent in people with ID relative to people without an ID. These included epilepsy (odds ratio $=31.03$ ), constipation (odds ratio $=11.19$ ), and visual impairment (odds ratio $=7.81)$. Yet it is important to note that the extent to which these outcomes will be expressed may be more or less linked to genetic aetiologies. That is, certain conditions (e.g. Prader-Willi Syndrome or Down's syndrome) might confer a particular risk of said comorbidity (e.g. obesity).

Regarding mortality, in a review of the deaths of 247 people with intellectual disabilities, Heslop and colleagues (2014) reported that the median age of death for men and woman with ID is, respectively, 13 years and 20 years lower than that in the general population. Moreover, $37 \%$ of these deaths were classified as "avoidable" through good quality healthcare. The percentage of avoidable deaths in the general population is approximately $13 \%$ (Heslop et al., 2014). Such alarming findings underscore the importance of annual health checks in this population. These checks are recommended for anyone aged 14 or older who has an established ID (Public Health England, 2016). Yet in 2017-2018 only just over half of patients with an ID received their annual health check (Thornton, 2019). The RCGP offers a step-by-step guide to conducting these checks (RCGP, n.d.). This guidance covers a range of topics relevant to both physical and mental health. Helpfully, this guide also offers a number of practical communication tips, which have been developed in conjunction with a patient with an ID. In a systematic review, Robertson and colleagues (2011) concluded that health checks are an effective method of recognising previously unidentified health problems in this population. 
Health checks are thus an evidence-based and effective service that GPs can offer their patients with ID.

\section{Mental health problems}

Like anyone else, people with ID can experience psychiatric illness such as depression or anxiety disorders. Common symptoms of these conditions include feelings of low mood, isolation, or anxiety. In contrast, conditions such as autism spectrum disorder, attention deficit hyperactivity disorder, and indeed ID are lifelong developmental differences. Grasping this distinction is important for a number of reasons, not least because it helps practitioners understand the configuration of service pathways and decision-making in prescribing.

Due to methodological variation between studies, there is a range of reports of the co-morbidity of ID and mental health problems. Nevertheless, the available research strongly indicates that children with ID experience rates of mental health problems which are comparable to or higher than neurotypical peers (Einfeld et al., 2011). Similar findings also extend to adults and adolescents with ID, with recent meta-analytic evidence estimating 33\% comorbidity (Mazza, Rossetti, Crespi, et al., 2019). Cooper and collaborators (2015) also describe specific cooccurring mental health conditions which people with ID experienced relative to people without an ID. These include schizophrenia (odds ratio $=7.16$ ), anxiety or other stress disorders (odds ratio $=2.62$ ) Dementia (odds ratio $=2.22$ ), and depression (odds ratio $=1.88$ ). Best practice guidelines thus recommend that a mental health review be completed as part of the patient's annual health check. (National Institute for Health and Care Excellence (NICE), 2016). The markers of a potential psychiatric disorder in people with ID are very varied, and include loss of skills, social isolation, avoidance, challenging behaviour, or loss of interest in activities the individual previously enjoyed (NICE, 2016). It is important to note that autism and ADHD, without ID, are themselves associated with increased psychiatric comorbidity.

\section{Challenging behaviour}

Challenging behaviour is also more common in people with ID (Emerson et al., 2010). Challenging behaviour is typically defined as "culturally abnormal behaviour(s) of such intensity, frequency or duration that the physical safety of the person or others is likely to be placed in serious jeopardy, or behaviour which is likely to seriously limit the use of, or result in them being denied access to ordinary community facilities" (Emerson 1995, p. 4). Several lines of evidence suggest that antipsychotic/psychotropic medications are commonly prescribed for people with ID, even in cases where the patient does not have a psychiatric diagnosis (Lunsky et al., 2018). Furthermore, in their study of UK primary care practices, Sheehan and colleagues (2015) observed challenging behaviour is independently associated with psychotropic prescribing after controlling for recorded psychiatric diagnosis. There is thus strong evidence that antipsychotics are used to manage behaviour in primary care without psychiatric indication. 
In response and as part of a wider national agenda to improve care for persons with an ID, the "stopping over medication of people with a learning disability, autism or both with psychotropic medicines (STOMP)" project was established (NHS England, n.d.). This project represents a collaboration between NHS England and other professional organisations including RCGP, The Royal College of Psychiatrists and The Royal Pharmaceutical Society. The core aims are as follows: a) promote regular check-ups about medication, b) ensure professionals involve patients and families in decision-making about medications c) inform all key stakeholders about alternative modes of intervention and responding to challenging behaviour (e.g. Positive Behavioural Support). It is therefore important that practitioners are aware of the various functions of challenging behaviours. That is, these behaviours very often serve a communicative or sensory function (National Institute for Health and Care Excellence, 2015). Moreover, the behaviours may be contextual or environmentally specific. NICE (2015) thus recommends that antipsychotic medication should only be offered if a) psychological or behavioural interventions have not been effective, b) treatment of any comorbid condition (psychiatric or otherwise) has not reduced the behaviour, c) there is significant risk to the safety of the individual or others (p15). The guidance goes on to state that these medications should only be offered in conjunction with psychological or other interventions. Further guidance and information on prescribing in primary care can be found in the RCGP annual health checks guide.

\section{Diagnostic overshadowing}

The now-popular clinical phrase "diagnostic overshadowing" has its provenance in early ID research. It is used to refer to situations where a symptom is misattributed to the patients' ID. This occurs throughout medicine but is particularly relevant in patients with ID when there is a well-documented and dangerous tendency for comorbidities such as constipation, epilepsy, infection are not sought as reasons for changes in behaviour. This can be fatal. Healthcare professionals thus have a moral ethical and professional responsibility to ensure that a patient's diagnosis of ID doesn't mean that they miss symptoms of underlying medical conditions. For instance, challenging behaviour in the form of head-banging might be how the individual expresses that they have a toothache, constipation, seizures, depression, sepsis or brain tumour. This is a significant contributor to avoidable death in people with ID (see Learning Disability Mortality Review 2019)

This can occur in the other direction, with ID not being sought because of other issues such as ASD or epilepsy. Therefore, GPs and other healthcare professionals also need to keep in mind that some patients with ID may reach adulthood without a diagnosis. Given the nature of the general practice, GPs are often well-placed to offer colleagues in other services a holistic view of the patient's physical and mental health. This level of insight can be operationalised to safeguard against possible diagnostic overshadowing in both primary care and specialist services.

\section{Service provision}




\section{Context}

In the 1970s, several clinical initiatives were established with the goal of deinstitutionalising of services for persons with mental health difficulties and or ID (Killaspy, 2007). Consequently, much of the responsibility for meeting the social and healthcare needs of such patients were gradually transferred to community-based teams. Often, however, community services were under-resourced and unable to respond to some of the specialist needs of this population. This contributed to many of these patients experiencing long stays in inpatient settings. In 2011, this issue came to the fore following the airing of the BBC Panorama documentary featuring Winterbourne View Hospital. This programme highlighted significant emotional and physical abuse committed by some staff against patients who had an ID. While the abuse was obviously abhorrent, it was also of great concern that patients with ID were spending long periods in inpatient units, rather than in the community. In response, the Department of Health (2012) developed the "Transforming care" plan wherein it pledged "all current placements will be reviewed by 1 June 2013, and everyone inappropriately in a hospital will move to community-based support as quickly as possible, and no later than 1 June 2014" ( P9). Unfortunately, however, this target was missed (Bubb, 2014).

Ultimately and despite the abuse uncovered at Winterbourne View Hospital, public outrage and subsequent policies and programmes, the numbers of patients with ID in inpatients units in the UK has remained at a similar level. Health and social care services for people with ID are still not delivering appropriate and timely support to enable people to lead flourishing lives in their local communities. It is the responsibility of all stakeholders, including GPs to ensure that whenever possible the needs of these patients are met in community-based settings which promote opportunities for inclusion, choice, and autonomy in a supportive environment. Moreover, frontline healthcare professionals such as GPs may be able to advise patients and families about the services available locally. GPs are also uniquely placed, given professional expertise and authority, to advocate for these patients both individually and at policy level.

\section{"Reasonable adjustments"}

There are various ways in which adjustments can be made to help patients with ID access GP surgeries. Regarding physical impairments, there is a need for practices to be accessible by alternative modes of transport such as wheelchairs and scooters. In addition, in a context where some patients with ID may have accompanying sensory issues, some patients may benefit from access to a sensory space whilst waiting. Such spaces may have special lighting or tactile objects designed to meet the sensory needs of these patients. People with ID may also benefit from communication passports to help professionals make reasonable adjustments. Organisations such as Promoting a More Inclusive Society (PAMIS) have developed such resources (see table 1). Further, people with ID should be given information in a form and through a media which is accessible to them and in line with their cognitive ability. This might include co-producing videos or leaflets about common health procedures. While many services have such information on their websites, a report by Turner and Robinson (2011) states that this information is not routinely offered. Crucially, these adjustments may benefit a wider group of patients, For instance, better, accessible information, thoughtfulness and tools to help with communication would help young adults, other marginalised groups like asylum seekers, 
members of the travelling community, homeless people and ex-drug users, people with dementia or people for whom English is not a first language. Other adjustments include extending and prioritising appointments. Further, GPs and other frontline staff may encourage patients with ID to write down or otherwise communicate what adjustments would make it easier for them to use the service prior to their visit. This is particularly important because of differences in experiences and assessment of pain in this population. For further reading on pain assessment for people with ID see Doody and Bailey (2017). Additional examples of adjustments to practice can be found at the General Medical Council website: www.gmcuk.org/ethical-guidance/ethical-hub/learning-disabilities\#learning-disabilites.

Recently, Dimensions (2018) conducted a survey of 252 GPs about their experiences caring for people with ID. The results indicated that $48 \%$ of GPs were unclear when to make a "reasonable adjustment" and 74\% suggest that they would benefit from further training. This suggests some training on "reasonable adjustments" may be beneficial. The survey also showed that $64 \%$ of GPs surveyed had less than 1 day's face-to-face training focused responding to the needs of patients with ID. And around 98\% indicated that they would like more training. Such training is available through charities and advocacy groups such as Dimensions or British Institute of Learning Disability (BILD). For a useful and accessible report on making reasonable adjustments see Turner and Robinson (2011).

\section{Services for people with ID across the lifespan}

When deciding which services may be beneficial for patients with ID, it is important to consider the nature of the ID (i.e. mild, moderate, serve, or profound) and the age of the patient.

Early intervention can be beneficial for some children with ID particularly in supporting carers and schools to understand and manage communication via behaviour, and in early identification and treatment of comorbidities. However, there is some geographical variation in the services that are available locally. Organisations such as the Early Intervention Foundation offer information regarding such services (see table 1 for details). Nevertheless, it is crucial that GPs understand the configuration of local ID services. For instance, some do not have a lower age limit but may only work with children up to the age of 18 with a moderate to a profound learning disability. Other community teams may work with any child with an ID (i.e. mild to profound) up to the age of 18 or 19. And some adult services may accept referrals from people 17 years and older with a learning disability or autism. Ensuring there is a continuity of service between child and adult services, is vital not only for patients with moderate to profound ID but also for patients with mild ID who may require support in activities of daily living as well as financial or legal decision-making.

Like anyone else, it is crucial that patients with ID have their wishes respected when it comes to their care, including end-of-life care. Groups such as the Marie Curie Foundation offer accessible guidance for professionals on a range of topics including communication of issues regarding end-of-life, supportive decision-making, and identifying distress. For further information see www.mariecurie.org.uk/professionals/palliative-care-knowledgezone/equality-diversity/learning-disability. 


\section{Working with carers and people with ID who attend independently}

It is important to consider that some patients with ID will attend appointments with carers, whereas others will attend independently. As described in The RCGP toolkit, carers can be valuable sources of information and can help practitioners restructure questions in a way that will be best understood by the patient. In addition, they can also help to confirm whether the information has been understood by the patient and suggest alternative modes of communication which the patient might prefer. Nevertheless, it is crucial that the patient is given the space and modes of communication to express their needs. And the carer should not answer for the patient when the patient is capable of expressing themselves. For patients with an ID who attend appointments without a carer, it is important that frontline professionals are mindful of when they had their last annual health check and allocate increased time to ensure that they are being understood and the patients have access to information in an accessible form. In this circumstance, it is particularly important that practitioners are proactive in offering and making reasonable adjustments.

Relatedly, issues around parenting and birth control might come to the fore when working with patients with ID. This raises a number of complicated moral and interdisciplinary issues regarding consent, patient autonomy, confidentiality, and attending to needs for support for both the parents as well as their children who may or may not also have ID. Such issues have been discussed elsewhere (e.g. Schuengel et al., 2017).

Despite being able to parent successfully, some mothers with ID report discrimination and not having their communication needs met during maternity consultations (Malouf et al., 2017). In addition to the material presented above, the Working Together with Parents Network also offers helpful resources that might be helpful when considering some of these issues www.bristol.ac.uk/sps/wtpn/forparents.

\section{Independent groups}

Independent charities and advocacy groups have done remarkable work pushing forward the disability rights agenda whilst offering specialist and important services to people with an ID. Such services include health and social care, housing, legal advice, employment, online chat forums, support groups, social activities and sports. Some of these groups are described in Table 1. This list is not exhaustive. Moreover, it is crucial to remember that, like anyone else, patients with ID can benefit from involvement in the suite of community activities, groups, and sports teams with people across the cognitive and behavioural spectrum.

\section{[Insert Table 1 here]}

\section{CONCLUSION}

Responding to the health inequalities faced by patients with an ID is a complex task that requires a coordinated and multi-pronged approach involving policymakers, health care 
professionals and clinically focused researchers. It is most important that patients and families are at the centre of decision-making about the services which are indeed "beneficial". GPs have a key role in reducing some of these health inequalities and can offer important services such as the annual health checks. Further, it is crucial that health care professionals across the care pathway are mindful and aware of potential abuses and overmedication of patients in this vulnerable population. At an individual level, staff training may prove a useful supplement to wider policy changes and clinical initiatives.

\section{Key Points}

- It is important that patients with an ID have this recorded in their health record

- People with ID often face a host of health inequalities and co-morbidity is common

- The annual health check is an important and effective services which GPs can offer their patients with ID

- Challenging behaviour is a complex multidimensional phenomenon which often serves a communicative or sensory function

- People with ID will benefit from person-centred support offered through community whenever possible

- Diagnostic overshadowing can be fatal

\section{References and further information}

Boat TF, Wu JT, of Behavioral D, et al. (2015) Clinical characteristics of intellectual disabilities. Mental Disorders and Disabilities Among Low-Income Children. National Academies Press (US).

Bubb S. (2014) Winterbourne View - Time for Change: Transforming the Commissioning of Services for People with Learning Disabilities and/or Autism. Available at www.england.nhs.uk/wp-content/uploads/2014/11/transforming-commissioningservices.pdf (accessed 23 September 2019).

Chang C-K, Chen C-Y, Broadbent M, et al. (2017) Hospital admissions for respiratory system diseases in adults with intellectual disabilities in Southeast London: a registerbased cohort study. BMJ Open 7(3): e014846. DOI:10.1136/bmjopen-2016-014846.

Cooper S-A, McLean G, Guthrie B, et al. (2015) Multiple physical and mental health comorbidity in adults with intellectual disabilities: population-based cross-sectional analysis. BMC Family Practice 16(1). DOI:10.1186/s12875-015-0329-3.

Department of Health (2012) Transforming Care: A National Response to Winterbourne View Hospital: Department of Health Review Final Report. Available at: https://assets.publishing.service.gov.uk/government/uploads/system/uploads/attachme nt_data/file/213215/final-report.pdf (accessed 23 September 2019).

Dimensions (2018) \#MyGPandMe - Making primary care fair. Available at: www.dimensions-uk.org/get-involved/campaigns/make-gps-accessiblemygpandme/report/ (accessed 16 September 2019).

Doody, O and Bailey M (2017) Pain and pain assessment in people with intellectual disability: issues and challenges in practice. British Journal of Learning Disabilities 45(3): 157-165. DOI: $10.1111 /$ bld.12189. 
Einfeld SL, Ellis LA and Emerson E (2011) Comorbidity of intellectual disability and mental disorder in children and adolescents: A systematic review. Journal of Intellectual and Developmental Disability 36(2): 137-143. DOI:10.1080/13668250.2011.572548.

Emerson E (1995) Challenging Behaviour: Analysis and Intervention in People with Learning Disabilities: Cambridge University Press.

Emerson E and Baines S (2010) Health inequalities and people with learning disabilities in the UK: 2010. Durham: Improving Health \& Lives: Learning Disabilities Observatory. Available at: https://pureportal.strath.ac.uk/filesasset/7402206/vid_7479_IHaL2010_3HealthInequality2010.pdf (accessed 24 September 2019).

Equality Act (2010) Equality Act (2010) The Stationery Office Limited, London. Available at: www.legislation.gov.uk/ukpga/2010/15/section/6 (accessed 6 November 2019).

Heslop P, Blair PS, Fleming P, et al. (2014) The Confidential Inquiry into premature deaths of people with intellectual disabilities in the UK: a population-based study. The Lancet 383(9920): 889-895. DOI: 10.1016/s0140-6736(13)62026-7.

Killaspy H (2007) From the asylum to community care: learning from experience. British Medical Bulletin 79-80(1): 245-258. DOI:10.1093/bmb/ld1017.

Lunsky Y, Khuu W, Tadrous M, et al. (2018) Antipsychotic use with and without comorbid psychiatric diagnosis among adults with intellectual and developmental disabilities. The Canadian Journal of Psychiatry 63(6): 361-369. DOI: $10.1177 / 0706743717727240$.

Malouf R, McLeish J, Ryan S, et al. (2017) 'We both just wanted to be normal parents': a qualitative study of the experience of maternity care for women with learning disability. BMJ Open 7(3): e015526. DOI: 10.1136/bmjopen-2016-015526.

Mazza MG, Rossetti A, Crespi G, et al. (2019) Prevalence of co-occurring psychiatric disorders in adults and adolescents with intellectual disability: A systematic review and meta-analysis. Journal of Applied Research in Intellectual Disabilities 00:1-3. DOI:10.1111/jar.12654.

Mulder PA, Huisman SA, Hennekam RC, et al. (2017) Behaviour in Cornelia de Lange syndrome: a systematic review. Developmental Medicine \& Child Neurology 59(4): 361-366. DOI: 10.1111/jar.12654.

NICE (2015) Challenging behaviour and learning disabilities: prevention and interventions for people with learning disabilities whose behaviour challenges. Available at: www.nice.org.uk/guidance/ng11 (accessed 2 July 2019).

NICE (2016) Mental health problems in people with learning disabilities: prevention, assessment and management. Available at: www.nice.org.uk/guidance/ng54/chapter/Recommendations\#annual-health-check (accessed 2 July 2019).

NHS (2019) General Medical Services (GMS) contract Quality and Outcomes Framework (QOF) Guidance for GMS contract 2019/20 in England. Available at: www.england.nhs.uk/wp-content/uploads/2019/05/gms-contract-qof-guidance-april2019.pdf. (accessed 6 November 2019)

NHS (2019) Learning Disability Mortality Review (LeDeR) Programme. (2019) Action from Learning. In: Improvement NEaN (ed). Available at: www.england.nhs.uk/wpcontent/uploads/2019/05/action-from-learning.pdf (accessed 24 September 2019).

NHS (n.d) Stopping over medication of people with a learning disability, autism or both (STOMP). Available at: www.england.nhs.uk/learning-disabilities/improvinghealth/stomp/ (accessed 6 July 2019). 
Public Health England (2015) People with learning disabilities in England 2015: Main report. Available at:

https://assets.publishing.service.gov.uk/government/uploads/system/uploads/attachme nt_data/file/613182/PWLDIE_2015 main_report_NB090517.pdf (accessed 2 July 2019).

Public Health England (2016) Annual learning disability health checks. Available at: www.gov.uk/government/publications/annual-health-checks-and-people-withlearning-disabilities/annual-health-checks-and-people-with-learning-disabilities. (accessed 2 July 2019).

Robertson J, Roberts H, Emerson E, et al. (2011) The impact of health checks for people with intellectual disabilities: a systematic review of evidence. Journal of Intellectual Disability Research 55(11): 1009-1019. DOI:10.1111/j.1365-2788.2011.01436.x.

RCGP. Clinical topic guide: neurodevelopmental disorders, intellectual and social disability. Available at: www.rcgp.org.uk/training-exams/training/gp-curriculum-overview.aspx (accessed 19 November 2019)

RCGP (n.d.) Health checks for people with learning disabilities toolkit. Available at: www.rcgp.org.uk/clinical-and-research/resources/toolkits/health-check-toolkit.aspx (accessed 24th September 2019).

Schuengel C, Kef S, Hodes MW, et al. (2017) Parents with intellectual disability. Current Opinion in Psychology 15: 50-54. DOI:10.1016/j.copsyc.2017.02.022.

Sheehan R, Hassiotis A, Walters K, et al. (2015) Mental illness, challenging behaviour, and psychotropic drug prescribing in people with intellectual disability: UK population based cohort study. Bmj 351: h4326.DOI:10.1136/bmj.h4326.

Thornton J(2019) People with learning disabilities have lower life expectancy and cancer screening rates. Bmj 364: 1404. DOI:10.1136/bmj.1404.

Turner S and Robinson C (2011) Reasonable Adjustments for People with Learning Disabilities. Available at: www.apictureofhealth.southwest.nhs.uk/wpcontent/uploads/reasonable-adjustments/Reasonable-Adjustments-for-people-withlearning-disabilities.pdf (accessed 9 July 2019).

World Health Organisation (2018) The ICD-10 classification of mental and behavioural disorders: clinical descriptions and diagnostic guidelines. Available at: https://icd.who.int/dev11/f/en\#/http\%3a\%2f\%2fid.who.int $\% 2$ ficd $\% 2$ fentity $\% 2$ f60526 $\underline{7007}$ (accessed 24 September 2019). 
Table 1: Independent groups

\begin{tabular}{|c|c|c|}
\hline Organisation & Services & Link to website \\
\hline $\begin{array}{l}\text { British } \\
\text { Institute of } \\
\text { Learning } \\
\text { Disability } \\
\text { (BILD) }\end{array}$ & $\begin{array}{l}\text { Bild is a national charity who advocate for } \\
\text { the rights of people with ID. They offer } \\
\text { training courses for professionals and } \\
\text { organisations. }\end{array}$ & $\begin{array}{l}\text { www.bild.org.uk/about- } \\
\underline{\text { bild/aboutbild }}\end{array}$ \\
\hline Dimensions & $\begin{array}{l}\text { Dimensions are a national charity who } \\
\text { provide a range of personalised services for } \\
\text { people with ID and their families. These } \\
\text { include supporting employment, } \\
\text { responding to challenging behaviour and } \\
\text { professional training. }\end{array}$ & $\begin{array}{l}\underline{\text { www.dimensions- }} \\
\underline{\text { uk.org/what-we-do }}\end{array}$ \\
\hline $\begin{array}{l}\text { Early } \\
\text { Intervention } \\
\text { Foundation }\end{array}$ & $\begin{array}{l}\text { Early Intervention Foundation is a charity } \\
\text { who advocate for early interventions as a } \\
\text { means to promote development }\end{array}$ & $\begin{array}{l}\text { www.eif.org.uk/about/who- } \\
\underline{\text { s-eif }}\end{array}$ \\
\hline Mencap & $\begin{array}{l}\text { Mencap is often considered the flagship ID } \\
\text { advocacy group in the UK. They offer a } \\
\text { range of services including, social care, } \\
\text { housing, employment, and an online } \\
\text { support group. }\end{array}$ & $\begin{array}{l}\text { www.mencap.org.uk/advice } \\
\text {-and-support/services-you- } \\
\underline{\text { can-count }}\end{array}$ \\
\hline PAMIS & $\begin{array}{l}\text { An organisation dedicated to offering } \\
\text { training and support for people and families } \\
\text { with complex and profound ID }\end{array}$ & $\begin{array}{l}\text { http://pamis.org.uk/services/ } \\
\underline{\text { digital-passports }}\end{array}$ \\
\hline
\end{tabular}

